\title{
QUANTIFYING ALUMINUM SCRAP GENERATION FROM SEVEN END-USE SECTORS TO SUPPORT SUSTAINABLE DEVELOPMENT IN CHINA
}

\author{
LIU, S. ${ }^{{ }^{*}}-$ LIANG, Y. $^{2}$ \\ ${ }^{1}$ Zhengzhou University of Aeronautics \\ No.15, West Wenyuan Road, Zhengdong New District, Zhengzhou, China \\ (phone: +86-134-6022-5539) \\ ${ }^{2}$ College of Management Science, Chengdu University of Technology \\ No. 1, Dongsan road, Erxian Bridge, Chenghua District, Chengdu, China \\ (phone: +86-156-7035-9739) \\ *Corresponding author \\ e-mail:liusl0223@sina.com
}

(Received 23 $3^{\text {rd }}$ Feb 2019; accepted $3^{\text {rd }}$ May 2019)

\begin{abstract}
Nowadays, the domestic mineral resources are short, and the ecological environment is becoming worse and worse. Besides, the trade protectionism is on the rise, and the international trade environment is uncertain and unsafe. This paper simulates the potential old scrap generated from actual aluminum products consumption of seven end-use sectors during 1996-2017 on the basis of Weibull distribution. The object is to facilitate the exploitation and cyclic utilization of old scrap and "urban mines". During this period, the building and construction (B\&C) and transportation (T) sectors are still the most and second consumers, accounting for $30 \%$ and $17 \%$ of the total consumption. Most aluminum products haven't entered into the scrapping stage yet, and only one fifth of consumed aluminum (about $52 \mathrm{Mt}$ ) became old scrap. In the in-use reservoir, $\mathrm{B} \& \mathrm{C}$ and $\mathrm{T}$ sectors take up about $60 \%$ due to their longer lifetime intervals. If the potential old scrap will be recycled efficiently, then the secondary aluminum produced by the scrap can meet around nine years' consumption demands at current consumption level. Therefore, the cyclic utilization of old scrap prompts resources saving, energy conservation, emission reduction and may remove the impacts of international trade instability. Keywords: aluminum resource, scrap generation, in-use stock, recycling and cyclic utilization
\end{abstract}

\section{Introduction}

Aluminum, a popular metal, and its alloys are applied widely all over the world. They are raw material sources of tens of thousands of products, and the production amount of aluminum nowadays is more than the sum of other nonferrous metals (Halvor, 2014). However, it has been produced in commercial quantities for just over 100 years (USGS, 2016) since the first electrolytic aluminium plant established by Pittsburgh, USA. So to speak, aluminum is a comparatively new industrial metal (USGS, 2016). In 1956, the world's aluminum production yield exceeded copper, ranking first among non-ferrous metals because of its wonderful characteristics (Chen et al., 2009a; Luca et al., 2013; USGS, 2016): light weight; excellent corrosion resistance and durability; no low-temperature brittleness and magnetism; good electrical conductivity and reflectivity; high thermal conductivity, and the like. Aluminum metal, its alloys and by-products are usually used in building \& construction (B\&C), transportation $(\mathrm{T})$, consumer durables 
(CD), containers \& packaging (C\&P), machinery \& equipment (M\&E), electrical engineering (EE), and other products. With the popularization of material lightweight requirement, aluminum metal and its alloys are more widely utilized, especially in national defense science field and some sophisticated industries such as aerospace engineering, medical apparatus and instruments, rail traffic and so on.

China, a populous and rapidly developing country, has the potential to influence the global material use (Wang et al., 2008). There is a significance increase in aluminum production and consumption amount after the reform and opening-up policy. During the period of 1991 to 2007, China's average growth rate of aluminum production and consumption was four times higher than the global average (Yue et al., 2014), especially after 2000, with the alumina and primary aluminum shares of global production rising from $9 \%$ and $13.2 \%$ in 2000 , to $37.7 \%$ and $51.1 \%$ in 2008 (Chen et al., 2010, 2012). China has long been the world's largest producer and consumer of aluminium (Yue et al., 2015). Nevertheless, China's bauxite reserves are only about 3 percent of the world's, and its per capita reserves are also small, one-tenth of the global average (Chen et al., 2008). They are mostly unserviceable diaspore, which are characterized by high aluminum, high silicon and low aluminum-silicon ratio. These characteristics increase the difficulty to mine and smelt bauxite ores, and lead to weak productivity growth (Chen et al., 2009b; Liu et al., 2011, Liu and Müller, 2012). As a result, China relies heavily on importing bauxite. In the previous study, its external dependence increased continuously, from $1.9 \%$ in 1996 to $40 \%$ in 2016 , among them $52.4 \%$ in 2007 and $54.3 \%$ in 2013 (Liu, 2017). The trade protectionism is on the rise, and the international trade environment is uncertain and unsafe. This situation is an obstacle to the realization of sustainable supply and sustainable economic and social development.

The supply structure of China's aluminum metal in recent years is about: $80 \%$ for primary aluminum, 20\% for recycled aluminum (Liu et al., 2016). And the average annual increase rate of secondary aluminum is above $25 \%$ after 1996 (Liu et al., 2016). Besides, the contribution degree of recycled aluminum supply is rising gradually (Liu, 2018). The energy required and pollution emission for producing secondary aluminum might be only $5-10 \%$ of that needed for smelting and producing primary aluminum (Melo, 1999). Remelting recycled aluminum can not only make up for the shortage of domestic bauxite ores, but also promote energy conservation and emissions reduction.

\section{Review of literature}

MFA is a systematic resource management means for stocks and flows of entire life cycle of materials within predefined anthropogenic temporal and spatial boundary (Brunner and Rechberger, 2004; Pauliuk and Müller, 2014; Nakamura and Halada, 2015; Maung et al., 2017; Wang et al., 2017). In recent years, it was extensively used in the research of noxious or specific chemical elements and in the fields of resources appropriate use and waste management. It usually divides the entire life cycle of elements into four main stages: Production (P); Fabrication \& Manufacture (F\&M); Use (U); and Waste Management \& Recycling (WM\&R) (Fig. 1).

Many experts and scholars use this approach to analyze non-ferrous metallic element such as iron (Wang et al., 2007), copper (Graedel et al., 2002; Spatari et al., 2002; Bertram et al., 2002; Rechberger and Graedel, 2002; Reck et al., 2006; Daigo et al., 2009), aluminum (Melo, 1999; Boin and Bertram, 2005; Hatayama et al., 2007; Dhalström and Ekins, 2007; Chen et al., 2009a,b, 2010; Chen and Shi, 2012; Chen and 
Graedel, 2012; Buchner et al., 2014), zinc (Graedel et al., 2005; Reck et al., 2006; Guo et al., 2010), lead (Mao et al., 2008a,b), phosphorus (Liu and Chen, 2006a,b) and the like. For the last few years, on the one hand, the studies on a more micro level (small scale of area, some kind or some certain kind of product) are more and more extensive. On the other hand, the WM\&R stage such as recovery amount, recovery rate, and recovery potential are hot topics (Hoyle, 1995; Gesing and Wolanski, 2001; Müller, 2006; Modaresi and Müller, 2012; Gu et al., 2016a,b).

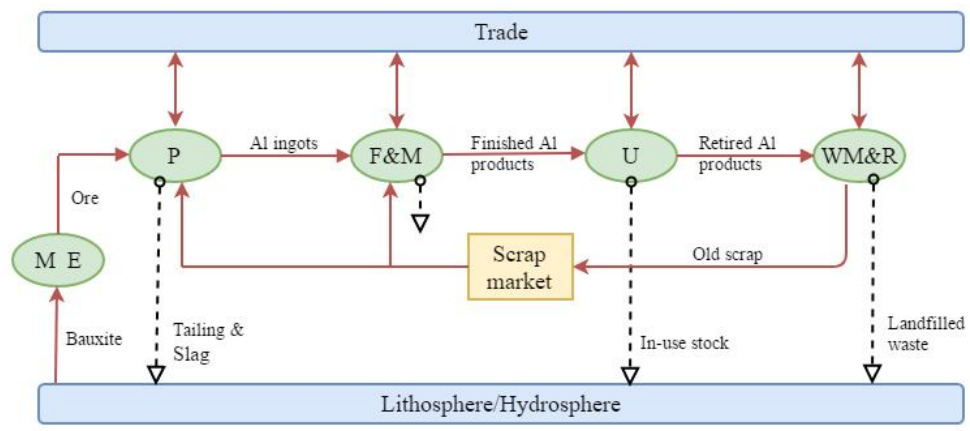

Figure 1. Simplified aluminum life cycle diagram (M E: Mine Extraction, P: Production; F\&M: Fabrication \& Manufacture; U: Use; WM\&R: Waste Management \& Recycling)

Among them, scrap generated from end-use sectors and in-use stocks of still existing in society are so complicated that researchers applied various methods to investigate them. McMillan et al. (2010) quantified aluminum in-use stocks and old scrap recycling and recovery in the United States for the period of 1900 to 2007 by a dynamic material flow analysis model and top-down approach. The in-use stock of aluminium in the State of Connecticut has been established by an extensive bottom-up study by Recalde et al. (2008), and the percentages of end-use sectors accounting for total stock have also been measured. Zhang et al. $(2012,2015 \mathrm{a}, \mathrm{b})$ mainly research on the flows and stocks of China's copper resource, and its spatial and temporal patterns by SFA, top-down, and bottom-up estimation. Yue et al. (2016) analyzed the iron in-use stocks in China by top-down and bottom-up methods, and related economic methods. Of course, estimation a sort of metal scrap and in-use stock of an industry is popular in researchers nowadays. The building stocks from urban to transnational scales was analyzed by Mastrucci et al. (2017) through bottom-up life cycle assessment, and Warrings and Fellner (2018) conducted a detailed material flow analysis for aluminum used in packaging \& household non-packaging in 2013 in Austria. A MS (material stocks) accounting for 10 materials in 6 major infrastructures in Beijing, Tianjin and Shanghai were conducted by Huang et al. (2017).

\section{Materials and methods}

The aluminum products transform into retired products and generate old scrap after serving for society for a while. Nevertheless, their lifetimes are diverse for end-use products of different categories, and this study adopts the following lifetime intervals in Table 1 on the basis of previous studies (Melo, 1999; Chen and Shi, 2012; Luca et al., 2013; Zhang et al., 2015a). Lifetime intervals of aluminum products are crucial for 
quantifying potential aluminum scrap, and Weibull distribution is proved to be a good way to simulate the life span of products. This paper applies the classical Weibull distribution to simulate the lifetimes of aluminum products from cradle to grave, and this is the foundation of aluminum scrap generation model.

Table1. Lifetimes of seven categories Al products assumed for this study

\begin{tabular}{c|c|c|c|c|c|c|c}
\hline & B\&C & T & CD & C\&P & M\&E & EE & Others \\
\hline Lifetimes & & & & & & & \\
\hline Low (a) & 23 & 10 & 5 & 1 & 10 & 10 & 5 \\
High (b) & 40 & 16 & 15 & 1 & 30 & 25 & 15 \\
\hline
\end{tabular}

The probability density function (pdf) of the Weibull distribution function in this study can be expressed in equation (1), and the scale and shape parameters are taken from some researchers as a reference (Melo, 1999; Chen and Shi, 2012; Luca et al., 2013; Zhang et al., 2015a; Wang et al., 2017). Thus it can be seen that the random variable $\mathrm{T}$ is described by three parameters: a location parameter $a$, a scale parameter $\alpha$, and a shape parameter $\beta$; and the mathematical constraint conditions of this function are $a \geq 0, \alpha>0, \beta>0$.

$$
f(t ; a, \alpha, \beta)=\left\{\begin{array}{cl}
\alpha \beta^{-\alpha}(t-a)^{\alpha-1} \exp \left\{-\left(\frac{t-a}{\beta}\right)^{\alpha}\right\}, & \text { if } t>a \\
0, & \text { otherwise }
\end{array}\right.
$$

If a product ends its service life in society and become to useless waste after $t$ years, then the probability of it is given by equation (2).

$$
p_{t}=\exp \left\{-\left(\frac{t-a}{\beta}\right)^{\alpha}\right\}-\exp \left\{-\left(\frac{t+1-a}{\beta}\right)^{\alpha}\right\}, a \leq t<b
$$

The value range $[\mathrm{a}, \mathrm{b}]$ of the distribution function is given by lifetime intervals in Table 1. In other words, $100 \%$ of the total area under the curve of the density function must be located within the ranges a and b. But the realistic situation is so complicated that not all of aluminum products will retire within $b$ years. So, this study stipulates that the cumulative distribution probability is set as $99.7 \%$, that is, $99.7 \%$ of the total area is under the density function curve within the lifetime interval [a,b]. The corresponding cumulative probability function $I P$ and the distribution function $F_{(t)}$ is measured by equations (3) and (4), and $\gamma=99.7 \%$.

$$
\begin{gathered}
I P(a \leq T \leq b)=1-\exp \left\{-\left(\frac{b-a}{\beta}\right)^{\alpha}\right\}=\gamma \\
F_{(t)}=1-\exp \left\{-\left(\frac{t}{\beta}\right)^{\alpha}\right\}
\end{gathered}
$$


Quantifying the scrap generation of end-of-life aluminum products is based on the Weibull distribution described above, and this paper adopts top-down method (McMillan et al., 2010; Park J-a et al., 2011; Yan et al., 2013; Müller et al., 2014; Chen and Graedel, 2015). The mechanism of scrap generation of end-of-life aluminum products is a very complex process, and this study simplifies it as: the finished aluminum products flow into society for multiple use, and they get retired after different given life spans. Therefore, the theoretical scrap generation of year $\mathrm{n}$ can be measured by equation (5):

$$
F_{(n)}^{\prime}=\exp \left\{-\left(\frac{n-1}{\beta}\right)^{\alpha}\right\}-\exp \left\{-\left(\frac{n}{\beta}\right)^{\alpha}\right\}
$$

Within this paper, the rate of theoretical old scrap generation in year $\mathrm{n}$ is assumed as $f_{(n)}$, the cumulative rate of which is $F_{(n)}$. Then $F_{(n)}^{\prime}$ refers to the probability of old scrap generation of aluminum end-of-life products (Park J-a et al., 2011; Yan et al., 2013). Besides, $\alpha$ and $\beta$ still represent scale parameter and shape parameter. There is a hypothesis that $T_{(t)}$ denotes the mount of realistic consumption of various aluminum-containing products in year $\mathrm{t}$, and $P_{(n)}$ is defined as the corresponding old scrap generation amount in year n. So $P_{(n)}$ can be expressed as equation (6):

$$
P_{(n)}=\sum_{t=0}^{n-1} T_{(t)} F_{(n-t)}^{\prime}
$$

The temporal boundary of this paper is the period of 1996-2017, the spatial boundary is mainland China, of course, and the major research objects are simulated aluminum old scrap generation for sum and end-of-life sectors. Most of various data used in calculation stems from official statistics, for example, the Yearbook of Nonferrous Metals Industry of China and World Bureau of Metal Statistics. Some missing data, especially aluminum products consumption amounts of seven end-use sectors, are borrowed from some reports and articles (Chen et al., 2009a, 2010; Chen and Shi, 2012; Yue et al., 2014).

In order to strengthen the scientific preciseness and conciseness of research, there are some assumptions and explanations: (1) This study just considers actual consumption statistics and focuses on old scrap generation of studied period of 1996-2017. That is, this study ignores the generated scrap from the years before 1996 and after 2017. (2) The length of service life of aluminum products follows the Weibull distribution. (3) The losses to the environment during the transformation from this flow into other flows are excluded from consideration.

\section{Results}

Nowadays, China is the country that produces and consumes the most aluminum metal, and the average growth rates of them are well above the world average (Yue et 
al., 2014). Fig. 2 clearly describes this phenomenon and the variation trend of consumption amounts of seven end-use sectors.

The total consumption amounts of aluminum metal in China have maintained a trend of continuous increase since 1996, even during in global financial crisis, and the average growth rate reaches up to $14.58 \%$. In China, the large-scale production and consumption of aluminum metal is relatively late, so the production and consumption of aluminum metal is very few before 1996. Besides, few consumption only generates fewer old scrap, and that is why the temporal boundary of this study begins in 1996.

Although the consumption amounts of seven end-use sectors all have been rising for decades, the consumption structure has also changed dramatically because of needs for economic and social development. From 1998 to 2000 was the period that has the most rapid changes in the consumption structure. Before 1998, the amounts of aluminum products in CD and EE fields were the most and second relatively, while the amount of aluminum products in B\&C field was far more than any other sector in 2000, accounting for a third of total consumption. After 2000, the consumption structure of seven fields also changed, but not too much.

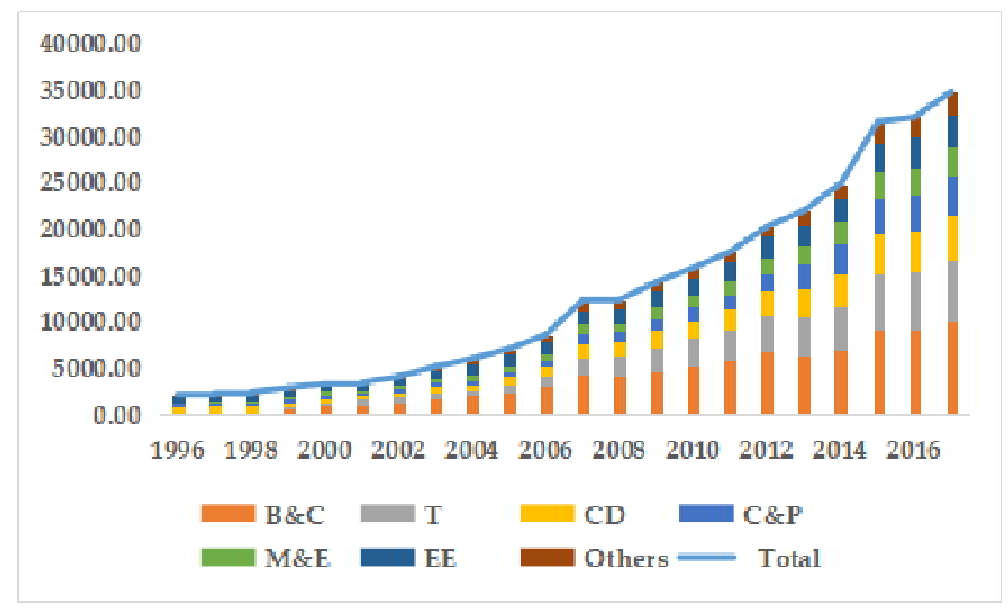

Figure 2. Consumption amounts of total and end-use sectors (Unit: kt)

The percentage of aluminum products in T sector was from less than $10 \%$ in 2000 up to $20 \%$ in 2017, nevertheless the percentage in EE sector was from about $20 \%$ in 2000 down to $10 \%$ in 2017 . In the period of 1996-2017, the cumulative consumption amounts of seven end-use sectors are around 87.7 Mt, 49.2 Mt, 39.1 Mt, 30 Mt, 25.5 Mt, 34.2 Mt, $20 \mathrm{Mt}$, respectively, and account for $30 \%, 17 \%, 14 \%, 10 \%, 9 \%, 12 \%$ and $7 \%$ of total consumption. At present, the $\mathrm{B} \& \mathrm{C}$ and $\mathrm{T}$ sectors are the two sectors that consume most aluminum metal, and they account for a half of total consumption. This situation is closely related to the general background of China's economic development: higher urbanization rates and convenient, comfortable, plentiful life for more people.

\section{Old scrap generation}

\section{Scrap generation of seven end-use sectors}

As we all know, the lifetime of aluminum-containing products in $\mathrm{B} \& \mathrm{C}$ sector is relatively long due to its durability, so theoretically, the consumption in the period of 
1996-2017 has not produced old scrap yet. The starting year and ending year of old scrap generation in B\&C sector are 2019 and 2056, respectively (Fig. 3).

The total amounts of annual potential scrap from B\&C sector rise smoothly and then fall gradually, the peak of which is at around 2043. Accordingly, the change trend of cumulative scrap amount is: increases slowly, increases rapidly and then remains at high position. The variation trends of potential scrap generation amounts annually and cumulatively from $M \& E$ and EE sectors are the same with B\&C sector, but the lifetime intervals are completely different. The starting year and ending year of old scrap generation in M\&E sector are 2006 and 2046, and they are 2006 and 2041 in EE sector. Besides, the peak of annual scrap generation amount in M\&E and EE sectors are all in about 2028 (Fig. 3).

The consumption quantity of aluminum products in $\mathrm{T}$ sector increases more and more rapidly because of the macro social background and lightweight requirement. The period of old scrap generation in T sector is from 2006 to 2032, and the annual scrap amount increases gradually, then increases quickly and drops more quickly after reaching the peak around 2027. The change trends of potential old scrap in CD and Others sectors are similar to the situation in T sector. Moreover, the periods of old scrap generation in these two sectors are all from 2001 to 2031, and the peaks are at around 2022. The tendency of the cumulative curve in these three fields is similar to other three fields described above, but the CD and Others fields increase smoothly, not increase slowly and then increase rapidly before reaching the high position. There is a striking common point in in these three fields: the growth change of annual scrap generation amount is not so regular. This is because their actual consumption amounts don't increase all the time before the peak, and they change unsteadily, sometimes more and sometimes less. However, the annual scrap generation in $\mathrm{B} \& \mathrm{C}, \mathrm{M} \& \mathrm{E}$ and $\mathrm{EE}$ fields increase little by little before reaching the peak.

Aluminum packaging materials can be said to be the most common aluminum products in life, but the mean lifetime of it is so short that the starting year and ending year of its old scrap generation are 1997 and 2018. This paper defined its lifetime interval as 1 year, therefore the annual scrap generation amount is closely related to the actual consumption of previous year. It's precisely because of its defined lifetime interval as well, the annual scrap generation amount augments all the time accompanying its consumption in the period of 1997-2018. Furthermore, the cumulative curve of C\&P sector is very different from other six sectors, and it is always on the rise. This situation also has to do with its lifetime interval.

\section{Annual and cumulative scrap generation}

From the bars of various colors in Fig. 4, the scrapping time nodes and scrap generation amounts of aluminum products of each sector can be obtained. In the beginning, only the aluminum products in C\&P sector enters the scrapping period, and the amount is nothing much.

Follow that, the aluminum products in $\mathrm{CD}$, Others, $\mathrm{T}, \mathrm{M} \& \mathrm{E}$ and $\mathrm{EE}$ sectors enter the scrapping periods successively, so there is a large growth in the annual scrap amounts. The latest aluminum products to enter the scrapping stage come from the $\mathrm{B} \& \mathrm{C}$ sector, and it's in 2019. However, the potential scrap decreases a lot in this year.

The fundamental cause of this phenomenon is that C\&P sector is completely out of scrapping stage. Due to the plentiful aluminum scrap generated from B\&C field, the total scrap has a big increase in amount. 


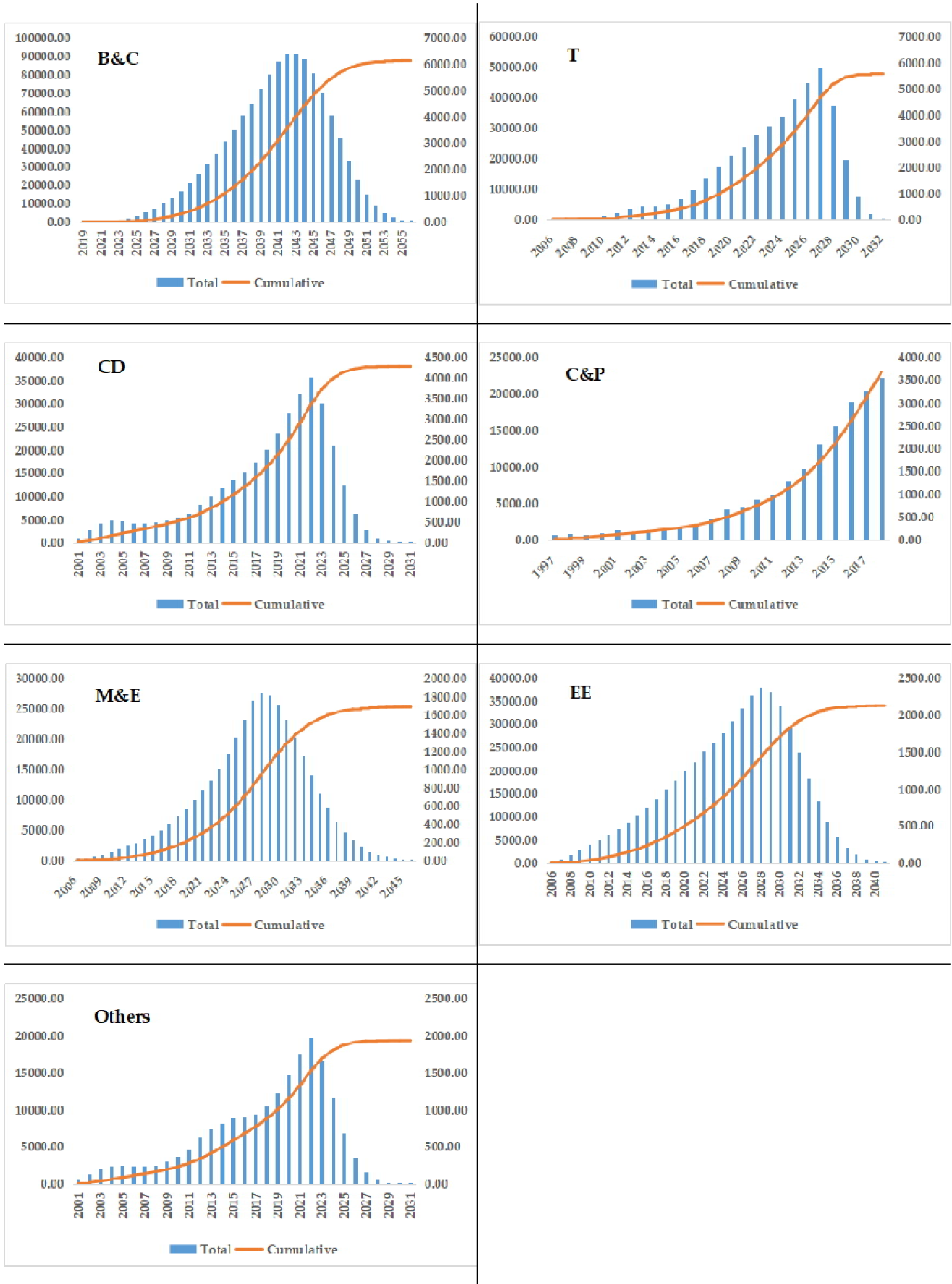

Figure 3. Theoretical old scrap generation of seven end-use sectors (In all charts, the starting year is the first time that the various consumed aluminum products entered the scrap stage, and the ending year is the last time. "Total" denotes the total scrap amounts annually, and "Cumulative" denotes the cumulative scrap amounts within the lifetime intervals. The larger scale values on the left describe "Cumulative", and the smaller scale values on the right describe "Total". Unit: kt) 
Then, the $\mathrm{CD}, \mathrm{T}$ and Others fields also gradually exit the scrapping stage, so the potential scrap from these three fields is on the decrease until around 2030. For a while after that, the theoretical scrap generated from $B \& C, M \& E$ and $E E$ sectors is near the maximum or at the maximum, so the annual scrap generation amount continues to increase until the $M \& E$ and $E E$ sectors exiting the scrapping period. In the end, there is $\mathrm{B} \& \mathrm{C}$ sector left, and the annual scrap generation amount is on the decrease step by step until it exiting the scrapping stage in about 2056. The complex old scrap generation amounts are attributed to the out-of-step of entering and exiting the scrapping stage of seven end-use sectors of aluminum products. There is no doubt that the cumulative amount increases continuously. The cumulative curve of the total potential old scrap in Fig. 4 is analogous to the cumulative curves of those six end-use sectors in Fig. 3: rises slowly, then rises rapidly, and remains at the high position.

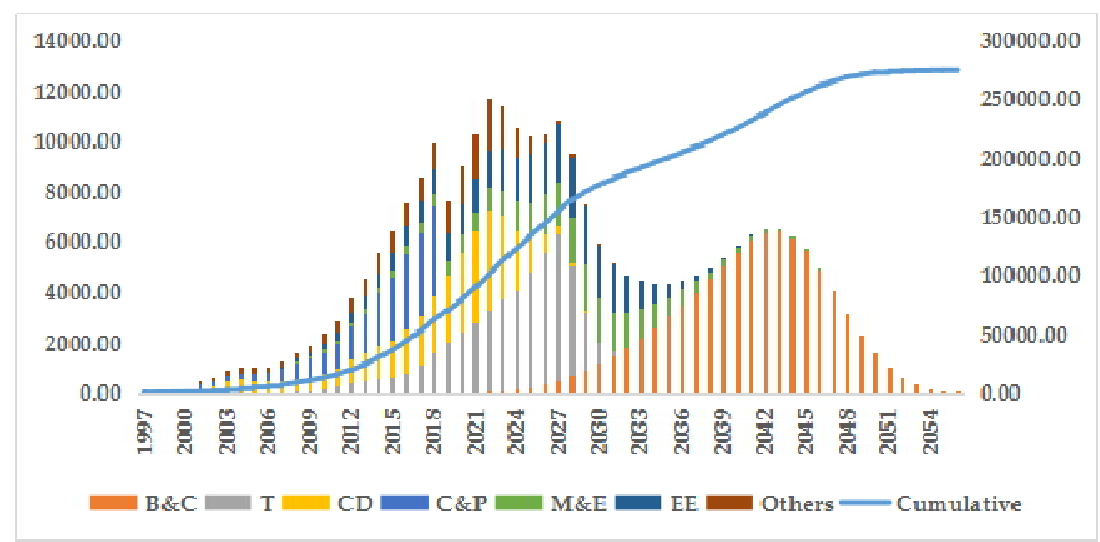

Figure 4. Annual and cumulative scrap generated from seven categories aluminum products consumption. (The larger scale values on the right describe "Cumulative", and the smaller scale values on the left describe "Annual". Unit: kt)

The total consumption of aluminum-containing products supports the twenty years' aluminum metal demands of the national economics. If most of the potential old scrap can be recycled, the secondary aluminum produced by it will meet nine years' consumption demands at current consumption level. It has a far-reaching significance for the country's sustainable development, and improves the ecological environment, reduces energy consumption and greenhouse gas emissions.

\section{In-use reservoir}

Theoretically, the cumulative old scrap generated from actual consumption in the period of 1996-2017 is 275 million tons, and the scrap generation amount before 2018 is about 52 million tons, accounting for one fifth or so. That is, there are four fifths of the theoretical old scrap still in the in-use reservoir, more than 220 million tons. The in-use stock is still under the ground to be mined, and will become the resource bank to support future consumption for economic development.

In in-use reservoir, there is no doubt that the largest proportion is in $\mathrm{B} \& \mathrm{C}$ field (Fig. 5), and $100 \%$ of them are still in anthropogenic cycle (Fig. 6) because they haven't entered into scrapping stage in the given period. It accounts for about $40 \%$ in the total in-use stock, and T sector followed by it. But the amount and percentage is only half of 
it, far less than B\&C field. Because it hasn't entered into a large-scale scrapping stage, most $(90 \%)$ of aluminum-containing products in $\mathrm{T}$ sector is still in use stage. This situation is closely similar to M\&E sector, however, it only accounts for about $10 \%$ in the total in-use stock. Besides, the slightly greater proportions in the in-use stock are EE and $\mathrm{CD}$ sectors, and the proportions are $13 \%$ and $11 \%$, respectively. But $86.5 \%$ of electrical engineering products and $63.3 \%$ of consumer durables are in the use stage. The aluminum products amount consumed by others sector is less than other fields, nevertheless the in-use stock quantity is not the least due to its longer lifetime interval. In addition, $60.2 \%$ of aluminum metal in others sector is still serving the society in different positions. The least in-use stock magnitude occurs in C\&P field, and its recycling period is very short. Although the year 2018 is its last recovery period, there are still $15.4 \%$ in the use stage. So the consumption quantity of aluminum packaging materials is large in last several years.

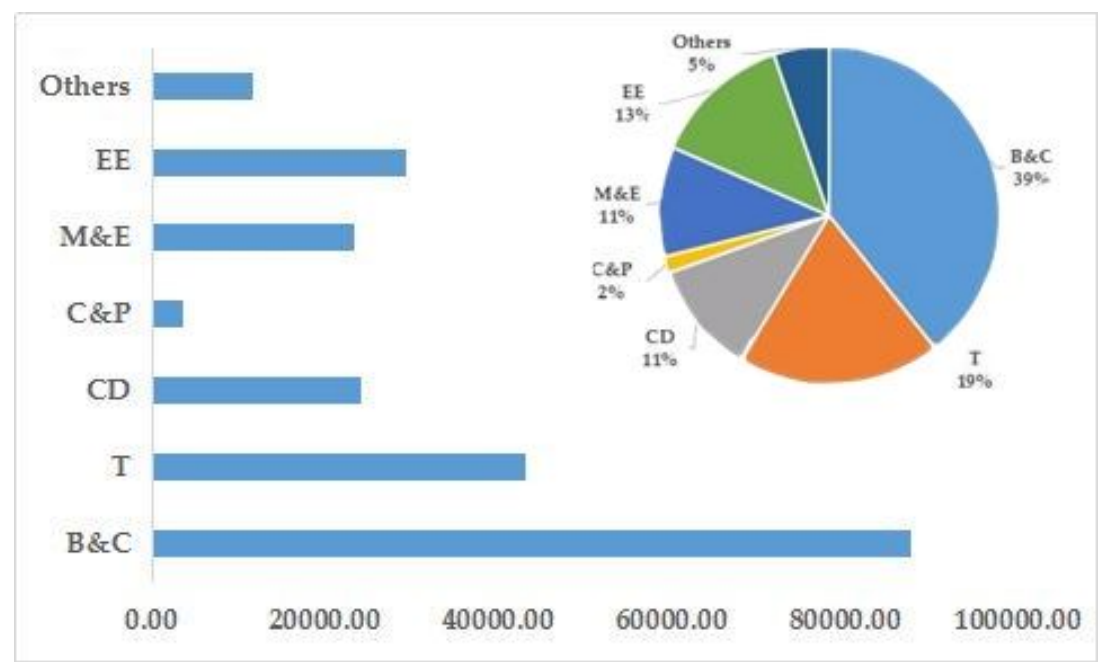

Figure 5. The amounts and percentages of in-use stock in seven end-use sectors. (Unit: kt)

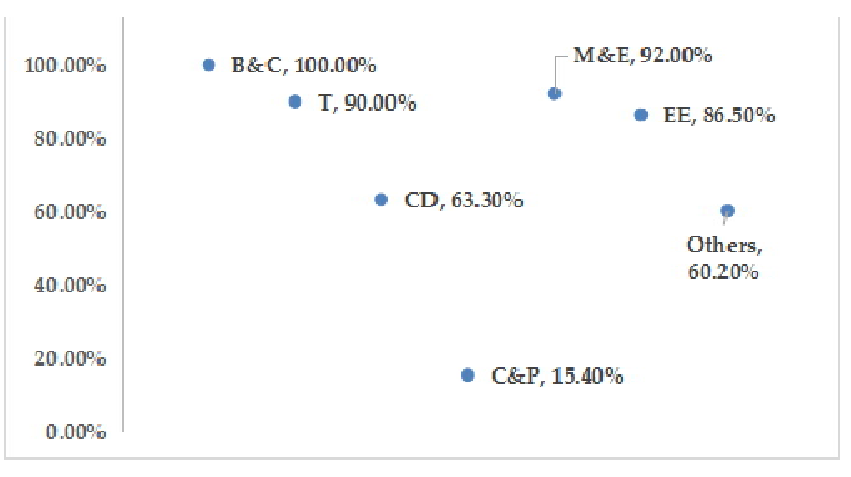

Figure 6. The percentages of in-use stock in their theoretical scrap generation

In general, the longer the lifetime interval, the more complex the scrapping process and the more uncertain the scrap generation. Therefore, the aluminum product consumed by $\mathrm{B} \& \mathrm{C}$ sector is more difficult to simulate its old scrap. On the contrary, the recovery rate of aluminum packaging materials is relatively high and is easy to calculate and utilize its old scrap. The research hot topics of old scrap and in-use stock 
management of aluminum products focus on the $\mathrm{B} \& \mathrm{C}, \mathrm{T}$ and $\mathrm{CD}$ fields, and other fields are studied much less than them due to the lack of detailed statistics, a variety of products, complicated models to be established difficultly and so on. If the recycling system is relatively sound and perfect, like some developed countries, these in-use stock will be cyclic utilized in all walks of life in the future and achieve the proposed closed-loop for resource use. The closed-loop aluminum resource utilization, on the one hand, saves substantial primary ore consumption; and on the other hand, also saves energy consumption, reduces greenhouse gas emission and the influence of international trade environment.

\section{Discussion}

In real production process, there are so many kinds of aluminum-containing finished products and intermediate products to meet the actual demands, and the lifetime intervals of them are very different from each other even though the same kind of products. So the lifetime intervals are far more complicated than the simplified scrapping time assumed in this paper. For example, a car should become the retired product in its eighth year, then to be recycled, dismantled and other treatments. However, it may be scrapped in its fifth or tenth year due to the various reasons, or some components and parts are directly applied in other products, not recycled. In a word, the anthropogenic cycle course for serving the society of aluminum metal is not easy to investigate clearly, and in general varieties of scholars apply lots of methods and models to simulate it.

The research temporal boundary of this paper is the period of 1996-2017, and the scrapping interval of those aluminum products is relatively longer. But the aluminum products in other years also generate old scrap in this scrapping stage, nevertheless this study only pays attention to the old scrap generated from the period of 1996-2017. Hence the actual annual and cumulative scrap amounts are entirely different from the results in Section 3, and in the meantime, this is also not a dynamic study to some extent. Furthermore, the calculations of potential scrap in this study are only based on the actual consumption of sum and seven end-use sectors, but the scrap generation amount is restricted and affected by many factors. This is also what needs to be improved in later research course.

Besides, the aluminum metal in-use stock is not $100 \%$ recycled after the service lifetime, some of which will become post-consumer waste or waste left in the remelting course, and they will be delivered to the landfills, metallurgical waste residue storage sites or the ecological environment. In addition, the loss of resources in the recycling process is also large such as transport, classify, dismantle, remelt and other treatments. Therefore, the cyclic utilization of resource is easier said than done, and the joint efforts of responsible departments and the public are required to bear the responsibility for reducing the resource waste, energy consumption and greenhouse gas emission.

\section{Conclusions}

In addition to the various costs of importing raw materials, the trade wars are also getting more and more intense, and the international trade environment becomes very uncertain. These factors will drive the increasingly chaotic international trade order, and 
importing raw materials will be more and more difficult. Therefore, the focus of acquiring resources ought to turn to the homeland, and exploit and utilize the domestic resource (old scrap and "urban mines").

This paper simulates the potential old scrap generated from actual aluminum products consumption of seven end-use sectors during the period of 1996-2017 on the basis of Weibull distribution. The main results and conclusions are as follows. (1) The $\mathrm{B} \& \mathrm{C}$ and $\mathrm{T}$ sectors are still the most and second consumers. The cumulative consumption amounts of seven end-use sectors $(\mathrm{B} \& \mathrm{C}, \mathrm{T}, \mathrm{CD}, \mathrm{C} \& \mathrm{P}, \mathrm{M} \& \mathrm{E}, \mathrm{EE}$, and Others) are around $87.7 \mathrm{Mt}, 49.2 \mathrm{Mt}, 39.1 \mathrm{Mt}, 30 \mathrm{Mt}, 25.5 \mathrm{Mt}, 34.2 \mathrm{Mt}, 20 \mathrm{Mt}$, respectively, and account for $30 \%, 17 \%, 14 \%, 10 \%, 9 \%, 12 \%$ and $7 \%$ of total consumption. (2) Most aluminum products haven't entered into the scrapping stage yet. Only one fifth of consumed aluminum (about $52 \mathrm{Mt}$ ) became old scrap, and the rest are serving the society in the form of in-use stock. In the in-use reservoir, B\&C and $\mathrm{T}$ sectors account for about $60 \%$ due to their longer lifetime intervals. (3) The percentages of in-use stock existing in those end-use sectors consumed in the period of 1996-2017 are $100 \%, 90 \%, 63.3 \%, 15.4 \%, 92 \%, 86.5 \%$ and $60.2 \%$. The majority of aluminum-containing products delay for supporting the country's economic development, industrialization and urbanization. (4) If the recycling system and related supporting policies are improved and completed, the potential old scrap will be recycled efficiently. Then the secondary aluminum produced by the scrap can meet around nine years' consumption demands at current consumption level.

In recent years, the government established a number of renewable resource industrial parks or ecological industrial parks along with the increasingly serious resource situation and promised energy conservation and emission reduction requirements. This is the successful experience of developed countries, and makes the waste recycling and reuse form a complete industrialization development model. The government needs to formulate various policies for key support, mainly from tax policy, technology research and development support policy, land use policy and other related supporting measurements, to overall coordinate the development of the industry. This industry will recycle generated old scrap and in-use reservoir to support domestic production and consumption, and drive the aluminum industry away from importing bauxite and scrap gradually to reduce the influence of international trade environment. However, the realities of aluminum products consumption, usage, retire, recovery, treatment and the like are so tanglesome that this study simplified the calculation model, and still has many shortcomings. In later course of research, these shortcomings will be made up step by step.

\section{REFERENCES}

[1] Bertram, M., Graedel, T. E., Rechberger, H., Spatari, S. (2002): The contemporary European copper cycle: waste management subsystem. - Ecol Econ 42: 43-57.

[2] Boin, U. M. J., Bertram, M. (2005): Melting standardized aluminum scrap: A mass balance model for Europe. - J Metals 57: 26-33.

[3] Brunner, P. H., Rechberger, H. (2004): Practical handbook of material flow analysis. Lewis Publishers: Boca Raton, FL, USA.

[4] Buchner, H., Laner, D., Rechberger, H. (2014): In-depth analysis of aluminum flows in Austria as a basis to increase resource efficiency. - Resour Conserv Recy 93: 112-123. 
[5] Chen, W. Q., Shi, L., Qian, Y. (2008): Description of anthropogenic aluminum cycles. Resources Science 30: 1004-1012. (in Chinese).

[6] Chen, W. Q., Shi, L., Chang, X. Y., Qian, Y. (2009a): Substance flow analysis of aluminum in China for 1991-2007 (I): Trade of aluminum from a perspective of life cycle and its policy implications. - Resource Science 31: 1887-1897. (in Chinese).

[7] Chen, W. Q., Wan, H. Y., Wu, J. N., Shi, L. (2009b): Life cycle assessment of aluminum and the environmental impacts of aluminum industry. - Light Metal 5: 3-10. (in Chinese).

[8] Chen, W. Q., Shi, L., Qian, Y. (2010): Substance flow analysis of aluminum in mainland China for 2001, 2004, and 2007: Exploring its initial sources, eventual sinks and the pathways linking them. - Resour Conserv Recy 54: 557-570.

[9] Chen, W. Q., Graedel, T. E. (2012): Dynamic analysis of aluminum stocks and flows in the United States: 1900-2009. - Ecol Econ 81: 92-102.

[10] Chen, W. Q., Shi, L. (2012): Analysis of aluminum stocks and flows in mainland China from 1950 to 2009: Exploring the dynamics driving the rapid increase in China's aluminum production. - Resour Conserv Recy 65: 18-28.

[11] Chen, W. Q., Graedel, T. (2015): Improved alternatives for estimating in-use material stocks. - Environ Sci Technol 49(5): 3048-3055.

[12] Daigo, I., Hashimoto, S., Matsuno, Y., Adachi, Y. (2009): Material stocks and flows accounting for copper and copper-based alloys in Japan. - Resour Conserv Recy 53: 208-217.

[13] Dhalström, K., Ekins, P. (2007): Combining economic and environmental dimensions: Value chain analysis of UK aluminum flows. - Resour Conserv Recy 51: 541-560.

[14] Gesing, A., Wolanski, R. (2001): Recycling light metals from end-of-life vehicle. - JOM 53: 21-23.

[15] Graedel, T. E., Bertram, M., Fuse, K., Gordon, R. B., Lifset, R., Rechberger, H., Spatari, S. (2002): The contemporary European copper cycle: The characterization of technological copper cycles. - Ecol Econ 42: 9-26.

[16] Graedel, T. E., van Beers, D., Bertram, M., Fuse, K., Gordon, R. B. (2005): The multilevel cycle of anthropogenic zinc. - J Ind Ecol 9: 67-90.

[17] Gu, Y. F., Wu, Y. F., Xu, M., Mu, X. Z., Zuo, T. Y. (2016a): Waste electrical and electronic equipment (WEEE) recycling for a sustainable resource supply in the electronics industry in China. - J Clean Prod 127: 331-338.

[18] Gu, Y. F., Wu, Y. F., Xu, M. (2016b): The stability and profitability of the informal WEEE collector in developing countries: A case study of China. - Resour Conserv Recy 107: $18-26$.

[19] Guo, X. Y., Zhong, J. Y., Song, Y., Tian, Q. H. (2010): Substance flow analysis of zinc in China. - Resour Conserv Recy 54: 171-177.

[20] Halvor, K. (2014): The aluminum smelting process. - J Occup Environ Med 56: S2-S4.

[21] Hatayama, H., Yamada, H., Daigo, I., Matsuno, Y., Adachi, Y. (2007): Dynamic substance flow analysis of aluminum and its alloying elements. - Mater Trans 48: 2518-2524.

[22] Hoyle, G. (1995): Recycling opportunities in the UK for aluminum-bodied motor cars. Resour Conserv Recy 15: 181-191.

[23] Huang, C., Han, J., Chen, W. Q. (2017): Changing patterns and determinants of infrastructures' material stocks in Chinese cities. - Resour Conserv Recy 123: 47-53.

[24] Liu, Y., Chen, J. N. (2006a): Substance flow analysis of phosphorus cycle system in China. - China Environmental Science 26: 238-242. (in Chinese).

[25] Liu, Y., Chen, J. N. (2006b): Substance flow analysis on phosphorus cycle in Dianchi basin, China. - Environment Science 27: 1549-1553. (in Chinese).

[26] Liu, G., Bangs, C. E., Müller, D. B. (2011): Unearthing potentials for decarbonizing the US aluminum cycle. - Environ Sci Technol 45: 9515-9522. 
[27] Liu, G., Müller, D. B. (2012): Addressing sustainability in the aluminum industry: a critical review of life cycle assessments. - J Clean Prod 35: 108-117.

[28] Liu, S. L., Li, X., Wang, M. X. (2016): Analysis of aluminum resource supply structure and guarantee degree in China based on sustainable perspective. - Sustainability 8(12): $1335-1351$.

[29] Liu, S. L. (2017): Dynamic analysis of aluminum flows in production stage in mainland China: 1996-2014. - Bulg Chem Commun 49 (Special Issue K1): 224-227.

[30] Liu, S. L. (2018): Contribution analysis of recycled aluminum supply in China based on sustainable supply. - IOP Conference Series: Materials Science and Engineering 397: 012107.

[31] Luca, C., Chen, W. Q., Fabrizio, P. (2013): Historical evolution of anthropogenic aluminum stocks and flows in Italy. - Resour Conserv Recy 72: 1-8.

[32] Mao, J. S., Dong, J., Graedel, T. E. (2008a): The multilevel cycle of anthropogenic lead I .Methodology. - Resour Conserv Recy 52: 1058-1064.

[33] Mao, J. S., Dong, J., Graedel, T. E. (2008b): The multilevel cycle of anthropogenic lead II . Recults and Discussion. - Resour Conserv Recy 52: 1050-1057.

[34] Mastrucci, A., Marvuglia, A., Leopold, U. (2017): Life cycle assessment of building stocks from urban to transnational scales: A review. - Renew Sust Energ Rev 74: 316-332.

[35] Maung, K. N., Yoshida, T., Liu, G., Lwin, C. M., Muller, D. B., Hashimoto, S. (2017): Assessment of secondary aluminum reserves of nations. - Resour Conserv Recy 126: 34-41.

[36] McMillan, C. A., Moore, M. R., Keoleian, G. A. (2010): Quantifying U.S. aluminum in-use stocks and their relationship with economic output. - Ecol Econ 69: 2606-2613.

[37] Melo, M. T. (1999): Statistical analyses of metal scrap generation: the case of aluminum in Germany. - Resour Conserv Recy 26: 91-113.

[38] Modaresi, R., Müller, D. B. (2012): The role of automobiles for the future of aluminum recycling. - Environ Sci Technol 46: 8587-8594.

[39] Müller, D. B. (2006): Stock dynamics for forecasting material flows-case study for housing in the Netherland. - Ecol Econ 59: 142-156.

[40] Müller, E., Hilty, L. M., Widmer, R. (2014) Modeling metal stocks and flows: a review of dynamic material flow analysis methods. - Environ Sci Technol 48(4): 2102-2113.

[41] Nakamura, T., Halada, K. (2015): Urban Mining Systems. - In: SpringerBriefs in Applied Sciences and Technology. Springer, Germany, Japan, pp 7-29.

[42] Park, J-a., Hong, S-j., Kim, I., Lee, J-y., Hur, T. (2011): Dynamic material flow analysis of steel resources in Korea. - Resour Conserv Recy 55(4): 456-462.

[43] Pauliuk, S., Müller, D. B. (2014): The role of in-use stocks in the social metabolism and in climate change mitigation. - Global Environ Chang 24: 132-142.

[44] Recalde, K., Wang, J. L. Graedel, T. E. (2008): Aluminium in-use stocks in the state of Connecticut. - Resour Conserv Recy 52: 1271-1282.

[45] Rechberger, H., Graedel, T. E. (2002): The contemporary European copper cycle: statistical entropy analysis. - Ecol Econ 42: 59-72.

[46] Reck, B. R., Bertram, M., Müller, D. B., Graedel, T. E. (2006): Multilevel anthropogenic cycles of copper and zinc: A comparative statistical analysis. - J Ind Ecol 10: 89-110.

[47] Spatari, S., Bertram, M., Fuse, K., Graedel, T. E., Rechberger, H. (2002): The contemporary European copper cycle:1 year stocks and flows. - Ecol Econ 42: 27-42.

[48] U.S. Geological Survey (2016): Aluminum Statistics and Information. http://minerals.usgs.gov/minerals/pubs/commodity/aluminum/.

[49] Wang, T., Müller, D. B., Graedel, T. E. (2007): Forging the anthropogenic iron cycle. Environ Sci Technol 41: 5120-5129. 
[50] Wang, T., Mao, J. S., Johnson, J., Reck, B. K., Graedel, T. E. (2008): Anthropogenic metal cycles in China. - J Mater Cycles Waste 10(2): 188-197.

[51] Wang, M. X., Chen, W., Zhou, Y., Li, X. (2017): Assessment of potential copper scrap in China and policy recommendation. - Resour Policy 52: 235-244.

[52] Warrings, R., Fellner, J. (2018): Current status of circularity for aluminum from household waste in Austria. - Waste Manage 76: 217-224.

[53] Yan, L. Y., Wang, A. J., Chen, Q. S., Li, J. W. (2013): Dynamic material flow analysis of zinc resources in China. - Resour Conserv Recy 75: 23-31.

[54] Yue, Q., Wang, H. M., Lu, Z. W., Zhi, S. K. (2014): Analysis of anthropogenic aluminum cycle in China. - T Nonferr Metal Soc 24(4): 1134-1144.

[55] Yue, Q., Du, Y., Wang, H. M. (2015): Analysis of Al-contents in social stock and the regeneration index of depreciated aluminum products. - J Northeast Univ (Nat Sci Ed) 36(9): 1297-1301. (in Chinese).

[56] Yue, Q., Wang, H. M., Gao, C. K. (2016): Analysis of iron in-use stocks in China. Resour Policy 49: 315-322.

[57] Zhang, L., Yuan, Z. W., Bi, J. (2012): Estimation of copper in-use stocks in Nanjing, China. - J Ind Ecol 16(2): 191-202.

[58] Zhang, L., Yang, J. M., Cai, Z. J., Yuan, Z. W. (2015a): Understanding the spatial and temporal patterns of copper in-use stocks in China. - Environ Sci Technol 49(11): 6430-6437.

[59] Zhang, L., Cai, Z. J., Yang, J. M., Yuan, Z. W. (2015b): The future of copper in China-A perspective based on analysis of copper flows and stocks. - Sci Total Environ 536: $142-149$. 